CENTRE for ECONOMIC

$P$ E R F O R M A N C E

CEP Discussion Paper No 746

August 2006

Trends in Hours and Economic Growth

L. Rachel Ngai and Christopher A Pissarides

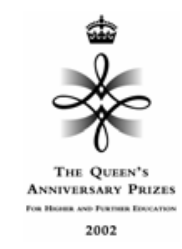




\begin{abstract}
We study long-run trends in market hours of work and employment shifts across economic sectors driven by uneven TFP growth in market and home production. We focus on the structural transformation between agriculture, manufacturing and services and on the marketization of home production. The model can rationalize the observed falling or Ushaped pattern for aggregate hours, the shift from agriculture to services and balanced aggregate growth. We find support for the model's predictions in long-run US data.
\end{abstract}

Keywords: hours of work, labour supply, structural transformation, home production, marketization, balanced growth

JEL Classification: J21, J22, O14, O41

This paper was produced as part of the Centre's Macro Programme. The Centre for Economic Performance is financed by the Economic and Social Research Council.

\title{
Acknowledgements
}

We have benefited from suggestions and comments from Francesco Caselli, Jeremy Greenwood, Gueorgui Kambourov, James Heckman, Robert Lucas, Torsten Persson, Danny Quah, Valerie Ramey, Richard Rogerson, Randy Wright and Fabrizio Zilibotti. We are especially grateful to Valerie Ramey for making available some of the data reported in Ramey and Francis (2006). An earlier version of this paper was presented as a keynote address at the CEPR/IZA annual labour economics conference at Ammersee in September 2005. We also acknowledge comments from presentations at the NBER meeting at the Cleveland Federal Reserve Bank, the IZA Prize Conference in Berlin, at the IIES and Stockholm School of Economics, at LSE, Arizona State University, and at the Universities of Kent, Rochester and Warwick. We thank Eva Vourvachaki for research assistance. This study was financed by the ESRC under award no. RES-000-22-0917.

L. Rachel Ngai is an Associate with the Macro Programme at the Centre for Economic Performance and a Lecturer in Economics, London School of Economics. Christopher A. Pissarides is Director of the Macro Programme at the Centre for Economic Performance. He is also Professor of Economics, London School of Economics.

Published by

Centre for Economic Performance

London School of Economics and Political Science

Houghton Street

London WC2A $2 \mathrm{AE}$

All rights reserved. No part of this publication may be reproduced, stored in a retrieval system or transmitted in any form or by any means without the prior permission in writing of the publisher nor be issued to the public or circulated in any form other than that in which it is published.

Requests for permission to reproduce any article or part of the Working Paper should be sent to the editor at the above address.

(C) L. R. Ngai and C. A. Pissarides, submitted 2006

ISBN 0753020521 
A feature of modern economic growth is the changing trend in total hours of work. In the early stages of modern growth total hours typically fall. In later stages trends become less clear-cut, with no systematic overall dynamic pattern. In the United States the trend over the last century appears to be a shallow U-shape, a steep decline followed by a small rise. In other countries there is a monotonic decline, although one that flattens out as growth progresses. A "stylized fact" of low-frequency fluctuations in market hours is that modern economic growth causes a long-lasting decline in mean hours, which eventually dissipates. Figure 1 uses data from the website of the Groningen Growth and Development Centre and shows average weekly hours of work for the population of working age. We show data for 1960-2004 for the United States and the biggest European economies. The main fact of a declining trend that either slows down or reverses is evident. Even more striking is the decline in hours before 1960, in the earlier stages of economic growth. Table 1 also shows weekly hours of work for the population of working age but for earlier periods. The rate of decline in the late 19th and early 20th century is striking. ${ }^{1}$

The changing trends in aggregate hours that one finds in long runs of data are usually neglected by modern growth theory. ${ }^{2}$ A seemingly unrelated feature of modern growth is structural transformation: the decline of agriculture and the rise of services, with relatively smaller changes in industrial employment. In this paper we propose a framework for the study of these two phenomena and posit that they are part of the same economic process: the response of hours of work to the uneven distribution of technological change across production sectors located in the market and the home. ${ }^{3}$

In our model work can be done both in the market and the home. We refer to the hours allocated to market work as the supply of labour and assume that it produces both consumption goods and capital goods. The time allocated to home production produces consumption goods by using capital goods purchased in the market but it

${ }^{1}$ The initial decline in market hours is typically driven by a rapid fall in the number of hours of work by those at work. In the United States this process went on until about 1940. The decline of agricultural employment, however, also contributes to the decline of total hours, through the withdrawal of some workers from the labour force, especially women and children. In more recent times there has been an increase in the labour force participation of women, which increased overall hours in the United States but less so in the European countries, where hours per employee continued to fall. See Durand (1975, esp. ch. 4) and Maddison (1995) for cross-country evidence and Goldin (1995) for female labour supply in the US time series and in other countries.

${ }^{2}$ A typical comment in the growth literature is the following one, due to Cooley and Prescott (1995, p.16): "In balanced-growth consumption, investment and capital all grow at a constant rate while hours stay constant. This behavior is consistent with the growth observations described earlier."

${ }^{3}$ Structural transformation has been studied by many authors. See Kuznets (1966) and Baumol (1967) for early contributions and Echevarria (1997), Kongsamut et al.(2001) and Ngai and Pissarides (2004) for more recent work. Home production has been studied extensively in a partial context, starting with Becker (1965) and Gronau (1977). More recently it has been studied in the context of equilibrium business cycles and to some extent in the context of growth (see Gronau 1997 for a survey and Parente et al. 2000 and Gollin et al. 2000 for growth-related work). 
Table 1: Weekly hours of work, population of working age

\begin{tabular}{ccccc}
\hline \hline Year & USA & France & Italy & UK \\
& & & & \\
1890 & 35.9 & 39.7 & 43.4 & 35.4 \\
1913 & 31.4 & 37.1 & 40.1 & 32.5 \\
1929 & 27.3 & 32.0 & 32.0 & 26.9 \\
1938 & 20.2 & 24.7 & 26.3 & 28.5 \\
1960 & 23.8 & 25.1 & 24.2 & 28.5 \\
\hline
\end{tabular}

The numbers shown are for the average weekly number of hours of market work for ages 15-64. Sources: Maddison (1995) for total hours and Mitchell (1980) and US Historical Statistics for the working age population.

is not part of the conventional definition of labour supply. We show that because of the uneven distribution of technological change the division of total work time between market and home is likely to change during the course of economic development. In our benchmark economy these changes drive the changes in aggregate labour supply. Under plausible conditions the time allocated to market production is likely to decrease in the early stages of modern growth but eventually it will increase. The prediction of a changing trend in the number of market hours is unique to our model: although a variety of mechanisms can yield a fall in market hours during economic growth, such as a rise in the returns to education or a rise in the demand for leisure, to our knowledge no model has been able to explain the turning point in market hours that we get from the substitutions between home and market production.

The intuition behind our results derives from the key assumption that although market activities at the disaggregation level of agriculture, manufacturing and services produce goods that are poor substitutes for each other, home production produces mainly goods that are close substitutes for goods produced in the market. Our utility function is defined over three composite goods, respectively corresponding to agricultural, manufacturing and service goods. Each composite is a basket of two goods, one of which is produced in the market and the other in the home. At the level of composites, employment is moving from agriculture and (eventually) manufacturing towards services, a process known as structural transformation. The reason is technology: because composite goods are poor substitutes for each other, employment moves to the sector with lowest TFP growth. But within each composite production is moving from the home to the market, a process that we call the marketization of home production. The reason for marketization is that TFP growth in the market is at least as high as TFP growth in the home, and given the high substitutability between the market- and home-produced goods, production efficiency requires that work be transferred from the home to the market. Combining these two forces we find that the home components of agricultural and manufacturing production, such as the cultivation of one's own food and the making of one's own clothes, are losing hours over time because both forces work against them. 
In contrast, the home component of services, such as cooking and shopping, is gaining hours because of the structural transformation in favour of total services, but as with the other sectors losing hours because of marketization. The tension between these two forces drives the dynamics of overall market hours. It explains why home production of agricultural and manufacturing goods disappears quickly and why the home production of services may rise at first but fall later.

We summarize US historical evidence that shows that the home production of agricultural and manufacturing goods practically disappeared in the first quarter of the 20th century. When this happened there was still a large agricultural sector so there was still a large movement of labour from agriculture to services. As agricultural employment declined, the hours of work allocated to the home production of services increased, albeit less than the increase in the hours allocated to the market production of services, which also benefited from marketization. Examples of home production that gained hours include cleaning, household administration, shopping and child care. ${ }^{4}$ But eventually, as agricultural employment shrank and the home service production sector grew, the marketization force became larger and dominated the structural transformation force, bringing a fall in the size of the home production sector. This process can explain an inverted U-shape for home production hours and reflecting this, a U-shape for market hours. If, for reasons not specified in our model, initially women are more likely to engage in home production than men are, these dynamic patterns can explain the fall in male hours of work in the first half of the century and the rise in female employment in the second.

In our benchmark model we make the conventional assumption that non-work time (i.e., all time other than market or home production) enters the utility function directly, and our utility function is such that in growth equilibrium non-work time is constant. During periods of transition to an aggregate balanced-growth equilibrium - following for example war or some other major event that disturbs the initial growth equilibrium changes in non-work time also contribute to changes in aggregate labour supply, but these periods cannot explain the long swings in labour supply that is the topic of this paper. We report calibrations with the steady state of our model which show that in the United States at least, substitutions between market sectors and between the market and the home can explain virtually all of the dynamics of sectoral employment shares and a significant part of the dynamics of market hours.

In an extension, however, we show how the model can yield a rising leisure time even when the economy is on a balanced growth path. The reason for pursuing this extension is that the substitutions between market and home do not explain the entire evolution in market hours, and it is plausible that some part of the big fall in hours of

\footnotetext{
${ }^{4}$ For example, Mokyr (2000) writes that at the beginning of the 20th century there was an increased demand for cleaner homes and better-prepared food, which required more home-production time. See section 1 for more historical evidence.
} 
market work that has taken place since the beginning of the 20th century was matched by rising leisure. ${ }^{5}$ The idea behind this extension is to divide leisure time into two components, one that is the pure enjoyment of time, as in conventional theory, and one that is enjoyment of time obtained with the help of some capital input. In the first group there are activities like spending time with friends or playing with one's children. In the second there are activities like watching TV and surfing the net. The key difference between the second leisure component and home production is that home production produces goods that have close substitutes in the market, whereas leisure production has no close market substitutes. One cannot outsource TV watching time. We show that the extended model implies a rising "leisure production time," which gives a rising overall leisure time. Consequently, market hours either fall faster or rise less than in our benchmark model.

Our model's explanation of the recent rise in labour supply is different from the one put forward by Greenwood et al. (2005) and more in line with the marketization force in Freeman and Schettkat (2005) and Rogerson (2004). Greenwood et al. show in a partial equilibrium model that labour supply increased because of substitutions from labour to capital in the home following a fall in the price of durable goods. In our model the price of durable goods also falls because of higher TFP growth in manufacturing than in services, but the substitution of capital for labour is not the driving force for the decline in home production time. The driving force is the marketization that takes place because similar goods can be produced more efficiently in the market. Of course, the two explanations are not mutually exclusive. An example that is consistent with our explanation is the observation that in the United States people consume more restaurant food than in Europe, where more food is prepared at home (see Freeman and Schettkat 2005 for more evidence of this kind). ${ }^{6}$

Section 1 examines some of the history of home production in the United States and discusses what types of goods are produced at home. Section 2 describes in detail our benchmark model, paying particular attention to the marketization and structural

\footnotetext{
${ }^{5}$ For example, it is unlikely that the big fall in weekly hours for the employed that took place in the first half of the century was matched one for one with a rise in home production time or education and training. For more formal evidence of rising leisure for individual groups in the post-war period see Robinson and Godbey (1997) and Aguiar and Hurst (2005). We do not attempt to say anything about the increase in education time because it would require a different type of model from the one that we have.

${ }^{6} \mathrm{~A}$ full test of the merits of each hypothesis is beyond the scope of this paper. Two potential tests are (1) a detailed examination of the relation between the introduction of household appliances and the decline of paid domestic help. Were household appliances "engines of liberation" for the housewife or "engines of job destruction" for low skilled labour? (2) A detailed examination of the behaviour of wages. In a decentralized economy our model would predict that women leave home production and join market production because female wages are rising. In the Greenwood et al. explanation the increased efficiency of home production releases time, which is now supplied to the market, so the impact should be from the increased supply of female labour to wages.
} 
transformation forces that shape the dynamics of hours. Section 3 discusses empirical implications and a numerical calibration based on US data on market shares and aggregate market hours. Section 4 discusses an extension with a richer leisure model that gives more general results about the dynamic behaviour of aggregate labour supply. In the concluding section we discuss some extensions, paying particular attention to the role of taxation and other distortions in the dynamics of labour supply.

\section{What is home production?}

Home production is defined as time spent on the production of goods and services, usually at home but sometimes outside, for one's own use. Two important properties of home production are (a) the individual derives utility from the output of home production but not from the time that she spends on it, and (b) home production can be "marketized", i.e., someone else can be paid to do it and the individual can still derive the same utility from its output. In contrast, leisure cannot be marketized, the individual has to spend the time herself to enjoy it.

It is important for our modelling that we know the relation between the goods produced at home and the goods produced in the market. The recent literature has focused mainly on aggregate models with one market good and one home-produced good, and argued convincingly that the two aggregates are close substitutes for each other. ${ }^{7}$ Here we have three market goods, agricultural goods, manufactures and services. How are home-produced goods related to each one of these? The early literature on home production was concerned with these issues, and a lot of useful information can be obtained from it. ${ }^{8}$

Obvious home production activities are cleaning, cooking and child care. In the early stages of economic development people also grew their own crops, kept small farm animals, made clothes and preserved food (Leeds 1917, Reid 1934). The crops grown at home were close substitutes for the output of the agricultural sector, and the clothes and food preservation were substitutes for manufacturing goods. There is overwhelming evidence, however, that in modern industrial societies virtually all home production is a substitute for services. These activities include shopping, looking after children and other relatives and administration (keeping bank accounts, dealing with bills, etc.).

Contemporary writers argue convincingly that with urbanization home-grown crops and rearing of small animals for food disappeared as home economic activities, even for those who worked on the farms. Of course, it would be unreasonable to argue that farm owners and farm workers do not consume any of their own products. But these products

\footnotetext{
${ }^{7}$ The most commonly used substitution elasticities between the two are in the range 1.5-2.3. See Rupert, Rogerson and Wright (1995), McGrattan, Rogerson and Wright (1997), and Chang and Schorfheide (2003).

${ }^{8}$ See among others, Leeds (1917), Reid (1934), Vanek (1973) and Labergott (1993).
} 
are grown for the market and are not the output of home production. In the statistics on farm employment the time devoted to growing this component of own food consumption is counted as market work, not non-market economic activity. The most data-consistent way to interpret the consumption of crops by those employed on the farms is as payment in kind. ${ }^{9}$

The home production of manufacturing goods was also overtaken by modern manufacturing technology early on in the industrialization process. Reid (1934 p.45) made the point forcefully: "After 1800 economic conditions changed rapidly. Roads improved steadily. Trade increased. Modern inventions made the most efficient tools too expensive for small-scale household use. Steam power possible only for centralized industries brought about the withdrawal of much manufacturing from the home." Some home manufacturing activities, however, survived into the twentieth century. Leeds (1917) writes that in his sample of 60 families in Pennsylvania, most families reported 2 to 3 hours a week making clothes for their own use. Although this included the work of paid domestic helpers, this was also an activity undertaken by the housewife. ${ }^{10}$ But seventeen years later, Reid (1934, p.47) summarized as follows the then-state of household production: "As time went on, one form of production after another, spinning, weaving, ... and other [manufacturing] tasks have wholly or in part been transferred to commercial production. In addition, child care, education, and the care of the sick are now to a large extent carried on by paid workers." In similar vein, Lebergott (1993, p.60) writes about the advent of "consumerism", by quoting a 1932 paper by Viva Belle Boothe, as arguing that "modern industrial processes have robbed the home of almost every vestige of its former economic function." Lebergott continued by noting that the remaining home work "consists largely of services."

The principal current home-production activities in the United States are shown in Table 2. These are all activities whose products are classified as services and which have close substitutes in the market services sector. No item in present-day time use surveys, either in Europe or elsewhere in the industrialized world, lists an activity that yields products that can be classified as either agricultural or manufacturing goods. The biggest item in the American surveys is shopping, followed by caring for other people in

\footnotetext{
${ }^{9}$ See Historical Statistics of the United States, Chapter D on labour: "Employed persons comprise: (a) all those who, during the survey week, worked at all as paid employee, in their own business or profession or on their own farm." Reid (1934, p. 48-51) argues that in the United States growing food specifically for own consumption disappeared as early as the 1920s. In the 1930 census of agriculture, the average proportion of total farm produce used by the operator's family was $13.6 \%$. But this was mainly market-grown food. "Home production farms", by which we mean small holdings that the owners used primarily to grow their own food, amounted to a mere $8 \%$ of all farms. Reid calls these "self-sufficing farms" and defines them as farms that the owners consumed over 50\% of output. In 1929 the average proportion of own consumption on these farms was $66.1 \%$.

${ }^{10}$ The total weekly hours of work in the household by the "housewife and her assistants, whether hired or members of the family" is 101.75 hours. 5.75 hours are for making clothes, and the rest are for activities that can only be classified as services. See Leeds (1917, p.67).
} 
Table 2: Weekly hours of home production, American Time Use Survey

\begin{tabular}{lclc}
\hline \hline Activity & Hours & Activity & Hours \\
Housework & 4.23 & $\begin{array}{l}\text { Purchasing goods } \\
\text { and Services }\end{array}$ & 5.67 \\
$\begin{array}{l}\text { Food preparation } \\
\begin{array}{l}\text { and clean up } \\
\text { Garden care }\end{array}\end{array}$ & 3.64 & $\begin{array}{l}\text { Caring for household } \\
\text { members }\end{array}$ & 3.83 \\
$\begin{array}{l}\text { Household } \\
\text { management }\end{array}$ & 0.95 & $\begin{array}{l}\text { Caring for non-household } \\
\text { members }\end{array}$ & 1.96 \\
\hline
\end{tabular}

The numbers shown are for the average weekly number of hours of home work for the population aged 15 and over for 2003 and 2004. Source: Bureau of Labor Statistics, http://www.bls.gov/tus/, Table 1.

and out of the household (presumably children and parents or relations living elsewhere). Moreover, although the time devoted to sub-categories changed over time, ${ }^{11}$ the broad categories of activities have not changed significantly since the 1930s.

In view of the historical evidence and evidence from modern time-use surveys, a good model of the allocation of time has to explain the reasons that home agricultural and manufacturing production have disappeared in modern industrial societies. It also has to explain why service production at home is surviving in such big numbers. We now describe such a model. As anticipated by the early writers, the driver is technology.

\section{A growth model with trends in hours}

Our argument can be developed in a simplified model where market work takes place in three differentiated sectors. An extension to more sectors is straightforward, at some notational cost. Agriculture and services produce only consumption goods. Total factor productivity growth is high in agriculture and low in services. Manufacturing produces the economy's capital stock and a consumption good. Home production can also produce three consumption goods with differentiated technologies, each of which is a good substitute for each of the consumption goods produced in the market. Capital goods cannot be produced in the home. Time has three uses - it can be used in market production, in home production or in leisure. ${ }^{12}$

\footnotetext{
${ }^{11}$ For example, there is now less time spent on cleaning and laundry but more time on shopping and household administration. See Vanek (1973) and Robinson and Godbey (1997).

${ }^{12}$ Thus we ignore the biggest fraction of the week, which is spent on essential physiological activities, mainly sleep, and which shows remarkable stability over time and across countries (about 70 hours). We also ignore schooling. See Juster and Stafford (1991) and Robinson and Godbey (1997).
} 
We derive the equilibrium as the solution to a social planning problem that maximizes the utility function of a representative agent. Equilibrium is defined as a set of dynamic paths for the allocation of capital and time to the three market sectors, home production and non-work time (leisure), and the allocation of the output of each sector to consumption and capital. The utility function of the infinitely-lived representative agent is

$$
U=\int_{0}^{\infty} e^{-\rho t}[\ln \phi(.)+v(1-l)] d t
$$

where $l \in(0,1)$ are per capita hours of total work (market and home), $v($.$) is the utility$ of leisure, with $v^{\prime}>0, v^{\prime \prime}<0$, and $v^{\prime} \rightarrow \infty$ as $l \rightarrow 1$, and $\phi($.$) is a CES aggregate over$ final consumption goods, defined by:

$$
\phi(.)=\left(\sum_{i=a, m, s} \omega_{i} c_{i}^{(\varepsilon-1) / \varepsilon}\right)^{\varepsilon /(\varepsilon-1)} .
$$

$c_{i}$ is the per capita consumption of a composite good, one each for agriculture, manufacturing and services, $\varepsilon>0$ is the elasticity of substitution between these composites, and $\omega_{i}>0, \sum \omega_{i}=1$. The consumption composites are combinations of the output of the market and home sectors for each good, respectively distinguished by a second subscript, $j=m, h$ :

$$
c_{i}=\left[\psi_{i} c_{i m}^{\left(\sigma_{i}-1\right) / \sigma_{i}}+\left(1-\psi_{i}\right) c_{i h}^{\left(\sigma_{i}-1\right) / \sigma_{i}}\right]^{\sigma_{i} /\left(\sigma_{i}-1\right)} \quad i=a, m, s .
$$

Here, $\psi_{i} \in(0,1), c_{i j} \geq 0 \quad \forall i, j$ and $\sigma_{i}>0$. The restrictions on the utility function are a combination of sufficient restrictions consistent with steady-state growth when leisure is endogenous and there are many consumption goods, previously derived by King et al. (1988) and Ngai and Pissarides (2004).

A key assumption is

$$
R 1: \sigma_{i}>1>\varepsilon \quad \forall i
$$

It implies that market and home-produced goods are close substitutes for each other but the agricultural, manufacturing and service goods are not close substitutes for each other. Generally, the three composite goods are distinct goods that households want to consume in near-constant proportions, but within each composite goods are only marginally differentiated and larger substitutions take place. We discuss some more evidence supporting $R 1$ in section 3.2 .

Our measure of total time is the total time available to the population who can work. We let $l_{i j}$ denote the share of that time allocated to each of the six production activities. Total market employment is $\sum_{\forall i} l_{i m} \equiv q$, which, in the absence of unemployment, is also the conventional definition of aggregate labour supply. Market employment shares are then defined by $l_{i m} / q$, for $i=a, m, s$. Facts about the aggregate labour supply are 
statements about the evolution of $q$, whereas structural change refers to changes in the market shares $l_{i m} / q$.

Production functions are identical in all activities except for their TFP parameters $A_{i j}$, which are Hicks-neutral:

$$
F^{i j}=A_{i j} F\left(l_{i j} k_{i j}, l_{i j}\right) ; \quad \dot{A}_{i j} / A_{i j}=\gamma_{i j} \quad i=a, m, s, \quad j=m, h .
$$

The production function $F$ has constant returns to scale, positive and diminishing returns to inputs, and satisfies the Inada conditions; $k_{i j}$ is the capital-labour ratio and $A_{i j}$ is TFP in each sector, with growth rate $\gamma_{i j}$.

All sectors produce consumption goods but only manufacturing produces capital goods. For convenience we split manufacturing into two sub-sectors, one producing consumption goods and the other producing only capital goods, with the same technology. With some abuse of notation we distinguish by subscripts $m m$ the component used in the production of consumption goods only and by $m k$ the component used in the production of capital goods. Because we are assuming constant-returns technologies and free factor mobility, this is equivalent to assuming one manufacturing sector whose output can be either consumed or invested:

$$
\begin{aligned}
c_{i m} & =A_{i m} l_{i m} f\left(k_{i m}\right) \quad i=a, m, s, \\
c_{i h} & =A_{i h} l_{i h} f\left(k_{i h}\right) \quad i=a, m, s, \\
\dot{K} & =A_{m m} l_{m k} f\left(k_{m k}\right)-(\delta+\nu) K, \\
\sum l_{i j} & =l, \quad i=a, m, s, \quad j=m, h, k, \\
\sum l_{i j} k_{i j} & =l k, \quad i=a, m, s, \quad j=m, h, k ;
\end{aligned}
$$

where in general $f(k) \equiv F(k, 1), \delta$ is the capital depreciation rate, $\nu$ is the population growth rate, $k$ is the ratio of the capital stock to hours of "total work" (the sum of market and home hours) and $K$ is the ratio of the aggregate capital stock to the population (so $k=K / l)$.

We obtain optimal allocations by maximizing the utility function in (1) subject to (5)-(10). The maximization can be described over three levels. At the highest level, the agent chooses a path for aggregate consumption (essentially for our composite $\phi$ ), hours of total work and the aggregate capital stock. Next, the aggregate capital stock and total work are allocated between the three composites $c_{i}(i=a, m, s)$ and capital production. And finally, the allocation to each $c_{i}$ is divided between market and home production. The conditions giving the allocations in the last two layers are "static". We start with the lowest level, the allocation between home and market, and move to the highest. 


\subsection{Optimal allocations between market and home: marketi- zation}

Suppose that the agent has allocated labour $l_{i}$ and capital per hour $k_{i}$ to the production of consumption composite $c_{i}$. What is the optimal allocation of these between home and market production? To find the answer we maximize (3) separately for each $i$ subject to the production functions in (6) and (7) and:

$$
\begin{aligned}
l_{i} & \geq l_{i h}+l_{i m} \\
l_{i} k_{i} & \geq l_{i h} k_{i h}+l_{i m} k_{i m} .
\end{aligned}
$$

Optimal allocations satisfy the first-order conditions

$$
\begin{aligned}
\frac{\psi_{i}}{1-\psi_{i}}\left(\frac{c_{i m}}{c_{i h}}\right)^{-1 / \sigma_{i}} & =\frac{A_{i h}}{A_{i m}}, \\
k_{i m} & =k_{i h} .
\end{aligned}
$$

Free capital and labour mobility imply that production efficiency is achieved at all times with equal capital-labour ratios between the home and the market. We can therefore drop the second subscript and write $k_{i}$ for the common capital-labour ratio in sector $i$ (in manufacturing it will be optimal to have the same capital-labour ratio in the production for capital goods, as we show below). Making use of the production functions and (13)-(14) we obtain:

$$
\frac{l_{i h}}{l_{i m}}=\left(\frac{1-\psi_{i}}{\psi_{i}}\right)^{\sigma_{i}}\left(\frac{A_{i m}}{A_{i h}}\right)^{1-\sigma_{i}} .
$$

Equation (15) contains the important "marketization" result of this paper: Because the relative TFP levels are changing over time, the employment shares in market and home production are also changing. By differentiation with respect to time we obtain:

$$
\frac{\dot{l}_{i m}}{l_{i m}}-\frac{\dot{l}_{i h}}{l_{i h}}=\left(\sigma_{i}-1\right)\left(\gamma_{i m}-\gamma_{i h}\right)
$$

With $\sigma_{i}>1$, and if TFP in the market sector is rising faster than in the home sector, the home sector is losing labour to the market sector. It implies that if the TFP growth rate of the market sector remains above the TFP growth rate of the home sector for a sufficiently long time, eventually the home sector will vanish and all consumption goods will be produced in the market. This is the basis of our claims about the marketization of all home production of agricultural and manufacturing goods. We return later in the paper to a discussion of the conditions needed for these results and to the question of the marketization of service production. 
From (15) we obtain the share of home production in composite good $i$ :

$$
\frac{l_{i h}}{l_{i}}=\frac{\left(\frac{1-\psi_{i}}{\psi_{i}}\right)^{\sigma_{i}}\left(\frac{A_{i h}}{A_{i m}}\right)^{\sigma_{i}-1}}{1+\left(\frac{1-\psi_{i}}{\psi_{i}}\right)^{\sigma_{i}}\left(\frac{A_{i h}}{A_{i m}}\right)^{\sigma_{i}-1}} .
$$

We give it here for future reference.

\subsection{Optimal sectoral allocations: structural transformation}

We now consider optimal allocations at the level of the composite sector. The analysis of the preceding section enables us to implement a convenient aggregation. Making use of (13) and (3) we derive the optimal relation between the consumption composite $c_{i}$ and the part of it produced in the market:

$$
\begin{aligned}
c_{i} & =z_{i}^{\sigma_{i}} c_{i m} \\
z_{i} & \equiv \psi_{i}^{1 /\left(\sigma_{i}-1\right)}\left[1+\left(\frac{1-\psi_{i}}{\psi_{i}}\right)^{\sigma_{i}}\left(\frac{A_{i h}}{A_{i m}}\right)^{\sigma_{i}-1}\right]^{1 /\left(\sigma_{i}-1\right)} .
\end{aligned}
$$

We note that $z_{i}$ depends only on parameters and it is a function of time because of its dependence on the ratio of home to market TFP. Similarly, from (15) we can write the aggregate $l_{i}$ allocated to sector $i$ in terms of the market allocation:

$$
l_{i}=l_{i m}+l_{i h}=\psi_{i}^{-1} z_{i}^{\sigma_{i}-1} l_{i m} .
$$

Therefore, we can aggregate the production functions in (6) and (7) into one for the composite $c_{i}$ :

$$
c_{i}=\psi_{i} z_{i} A_{i m} l_{i} f\left(k_{i}\right) \quad i=a, m, s .
$$

Maximization at the level of the sector takes place by maximizing $\phi($.$) in (2) for$ given $l$ and $k$, with controls $c_{i}, l_{i}, k_{i}, l_{m k}$ and $k_{m k}$. The constraints are (21) and as before, (8)-(10), noting that $l_{i m}+l_{i h}=l_{i}$ and $k_{i m}=k_{i h}$.

Maximization with respect to the factor inputs yields

$$
k_{m k}=k_{i}=k \quad i=a, m, s,
$$

so capital-labour ratios are common in all production activities. Maximization over the consumption allocations yields,

$$
\frac{\phi_{i}}{\phi_{j}}=\frac{\psi_{j} z_{j} A_{j m}}{\psi_{i} z_{i} A_{i m}} \quad i, j=a, s, m,
$$


where the notation is in general $\phi_{i}=\partial \phi / \partial c_{i}$. Given the definition of $\phi$ in (2), we can write

$$
\frac{c_{i}}{c_{j}}=\left(\frac{\omega_{i} \psi_{i} z_{i} A_{i m}}{\omega_{j} \psi_{j} z_{j} A_{j m}}\right)^{\varepsilon},
$$

and from this equation and (21) we can get:

$$
\frac{l_{i}}{l_{j}}=\left(\frac{\omega_{i}}{\omega_{j}}\right)^{\varepsilon}\left(\frac{\psi_{j} z_{j} A_{j m}}{\psi_{i} z_{i} A_{i m}}\right)^{1-\varepsilon} .
$$

This equation is the basis of the structural transformation force. Traditionally, structural transformation is discussed in the context of market hours of work only. For market hours the equation is derived from (25) by making use of (17):

$$
\frac{l_{i m}}{l_{j m}}=\left(\frac{\omega_{i} \psi_{i}}{\omega_{j} \psi_{j}}\right)^{\varepsilon} \frac{z_{j}^{\sigma_{j}-\varepsilon}}{z_{i}^{\sigma_{i}-\varepsilon}}\left(\frac{A_{j m}}{A_{i m}}\right)^{1-\varepsilon} .
$$

We note that if there is no home production of goods $i$ and $j$, i.e., if $\psi_{i}=\psi_{j}=1$, then $z_{i}=z_{j}=1$, equations (25) and (26) become identical and the structural transformation force is:

$$
\frac{i_{i}}{l_{i}}-\frac{i_{j}}{l_{j}}=(1-\varepsilon)\left(\gamma_{j m}-\gamma_{i m}\right) .
$$

For $\varepsilon<1$, sectors with fast TFP growth are losing labour share to sectors with low TFP growth, unlike the marketization force, which gives a movement in the opposite direction.

When there is home production the dynamics of $z_{i}$ also matter in sectoral allocations. By differentiation of the expression for $z_{i}$ in (19) we obtain:

$$
\begin{aligned}
\frac{\dot{z}_{i}}{z_{i}} & =\left(\gamma_{i h}-\gamma_{i m}\right) \frac{\left(\frac{1-\psi_{i}}{\psi_{i}}\right)^{\sigma_{i}}\left(\frac{A_{i h}}{A_{i m}}\right)^{\sigma_{i}-1}}{1+\left(\frac{1-\psi_{i}}{\psi_{i}}\right)^{\sigma_{i}}\left(\frac{A_{i h}}{A_{i m}}\right)^{\sigma_{i}-1}} \\
& =\left(\gamma_{i h}-\gamma_{i m}\right) \frac{l_{i h}}{l_{i}}
\end{aligned}
$$

where use has been made of (17). Bringing now results together, by differentiating (25) with respect to time and making use of $(29)$, we obtain:

$$
\begin{aligned}
\frac{i_{i}}{l_{i}}-\frac{i_{j}}{l_{j}} & =(1-\varepsilon)\left(\gamma_{j}-\gamma_{i}\right) \quad i, j=a, m, s . \\
\gamma_{j} & \equiv\left(1-\frac{l_{j h}}{l_{j}}\right) \gamma_{j m}+\frac{l_{j h}}{l_{j}} \gamma_{j h} .
\end{aligned}
$$


A comparison with (27) shows that when there is a home sector the TFP growth rates of the market sectors are replaced by the weighted average of the TFP growth rates of the market and home sector. It is clear from the definition of $\gamma_{j}$ that we need some quantitative restrictions on TFP growth rates to sign the direction of labour movement. We return to this question in section 3.

We now solve for the sectoral distribution of employment and capital for given aggregate $l$ and $k$. From (22), capital is distributed such that capital-labour rations are equal in all sectors. But given $k_{m k}=k$, employment in the capital-producing sector is immediately obtained by inverting the production function, since the output of the sector is given by the assumption, made so far, that the path of the aggregate capital stock is given. Therefore, the distribution of employment in the consumption-producing sectors satisfies equations (25) for a given total allocation of time $l-l_{m k}$. The solution for each sector's employment follows immediately:

$$
\frac{l_{i}}{l-l_{m k}}=\frac{\omega_{i}^{\varepsilon}\left(\psi_{i} z_{i} A_{i m}\right)^{-1+\varepsilon}}{\sum_{\forall j} \omega_{j}^{\varepsilon}\left(\psi_{j} z_{j} A_{j m}\right)^{-1+\varepsilon}}
$$

With knowledge of $l_{i}$ the hours of work in market and home production are obtained from (20), completing the description of equilibrium at this level.

\subsection{Aggregate growth}

Aggregate equilibrium is obtained by defining per capita aggregate consumption of all goods in terms of the manufacturing market price. The objective is to aggregate up from the composite goods such that the utility function (1) and dynamic constraint (8) become functions of aggregate consumption, the aggregate capital stock and non-work time.

We first obtain the aggregate utility function. Because of the competitive allocations that we have assumed, the price of consumption composite $i$ in terms of the manufacturing market price is equal to the marginal rate of substitution $\phi_{i} / \phi_{m m}$. We define aggregate per capita consumption as follows:

$$
c \equiv \sum_{i=a, m, s}\left(\frac{\phi_{i}}{\phi_{m}}\right)\left(\frac{\phi_{m}}{\phi_{m m}}\right) c_{i} .
$$

The first MRS is obtained from (23) and the second by differentiation of (2) and (3) and use of (18). The relative price of composite $i$ to the manufacturing market price that we obtain is $A_{m m} /\left(\psi_{i} z_{i} A_{i m}\right)$. From (21) we then derive:

$$
c=A_{m m} f(k)\left(l-l_{m k}\right) .
$$

From (21) again and (32) we obtain

$$
\frac{c_{i}}{c}=\frac{\left(\omega_{i} \psi_{i} z_{i} A_{i m}\right)^{\varepsilon}}{A_{m m} \sum_{\forall j} \omega_{j}^{\varepsilon}\left(\psi_{j} z_{j} A_{j m}\right)^{\varepsilon-1}} .
$$


We use (35) to substitute all $c_{i}$ out of $\phi$. Because $\phi$ is homogeneous of degree 1 we can write $\phi=c \tilde{\phi}($.$) , where \tilde{\phi}($.$) is a function of parameters (albeit changing over time).$

The aggregate constraints are (34), the definition $k=K / l$, and (8). We substitute (34) into (8) to obtain the single constraint that describes the evolution of the aggregate state variable:

$$
\dot{K}=A_{m m} l f(K / l)-c-(\delta+\nu) K .
$$

We also define the new maximand, derived from (1) and $\phi()=.c \tilde{\phi}($.$) ,$

$$
\tilde{U}=\int_{0}^{\infty} e^{-\rho t}[\ln c+v(1-l)] d t .
$$

Aggregate equilibrium is defined as the paths of $c, l$ and $K$ that maximize (37) subject to $(36)$.

Inspection of the maximization problem shows that it has the structure of the maximization problem of the one-sector Ramsey economy, except for one difference: technological growth in the Ramsey economy needs to be labour-augmenting but here it is Hicks-neutral. We therefore assume that the production function is Cobb-Douglas, which make the two equivalent: $f(k)=k^{\alpha}$. Under this assumption there are unique convergent paths for $c, l$ and $K$ and a balanced-growth equilibrium with $l$ constant and $c$ and $K$ growing at the rate of labour-augmenting productivity growth in manufacturing, $\gamma_{m m} /(1-\alpha)$. Once the equilibrium paths for the aggregates are known, the rest of the model is solved by working backwards through our derivations: the evolution of the consumption composites is given by (35) and their breakdown between home and market consumption by (18). The capital-labour ratio in all production activities is given by $k=K / l$ and the evolution of hours of work used in the production of capital goods by (8). With knowledge of $l$ and $l_{m k}$, (32) gives employment in the production of each composite good $i$ and (17) gives its breakdown between home and market, completing the description of equilibrium.

\section{Empirical implications and other properties}

\subsection{Qualitative properties and aggregate facts}

It is straightforward to show with standard techniques that the stationary equilibrium of the aggregate maximization problem is saddlepath-stable. In a diagram with hours of work on the vertical axis and capital per efficiency unit on the horizontal the saddlepath is downward-sloping, which implies that in the adjustment to equilibrium hours of work are falling. But given our interest in long-run trends, it is more interesting to look at the properties of steady-state equilibrium. On the steady state hours of total work are constant. We still get changing hours of market work which are compensated by changes in hours of home production. 
There is a close relation in our model between consumption and non-work time, given by

$$
\frac{c}{y}=\frac{1-\alpha}{v^{\prime}(1-l) l}
$$

where $y$ is aggregate per capita output, defined analogously to aggregate per capita consumption, in terms of the manufacturing market price:

$$
y=c+A_{m m} l_{m k} k^{\alpha}=A_{m m} l k^{\alpha} .
$$

Since in this expression $A_{m m} k^{\alpha-1}$ is constant in the steady state, $l_{m k}$ must also be constant and $y, c$ and $k$ growing at the same rate. So the following allocations are constant in our steady state: total hours of work allocated to the production of consumption goods, total hours allocated to the production of capital goods and total hours of nonwork time. But market hours are defined by $q \equiv \sum_{\forall i} l_{i m}+l_{m k}$, and so are changing over time.

If we restrict attention to the market sector, we find that the capital-output ratio is also constant and output per hour growing at constant rate. The aggregate capital stock in the market sector is given by

$$
K_{\text {market }}=\sum_{\forall i}\left(l_{i m}+l_{m k}\right) k=q k,
$$

and so the market capital-labour ratio, $K_{\text {market }} / q$ is simply $k$. Market output in this economy is

$$
y_{\text {market }}=\sum_{\forall i}\left(\frac{\phi_{i m}}{\phi_{m m}}\right) A_{i m} k^{\alpha} l_{i m}+A_{m m} k^{\alpha} l_{m k}=q A_{m m} k^{\alpha}
$$

and so market output per hour, $y_{\text {market }} / q$ is growing at the same constant rate as the other aggregates and the capital-output ratio in the market economy is constant. This confirms our claim that our economy satisfies Kaldor's stylized facts of aggregate balanced growth, despite the changes in labour supply.

We now discuss some important qualitative properties of hours of work by making the following assumptions on productivity growth rates:

$$
\begin{aligned}
R 2 m & : \gamma_{a m} \geq \gamma_{m m}>\gamma_{s m} \\
R 2 h & : \quad \gamma_{i m} \geq \gamma_{i h} \quad \forall i .
\end{aligned}
$$

$R 2 m$ is consistent with the observed fact that the price of services is rising faster, and the price of agricultural goods slower, than the price of manufacturing goods. ${ }^{13}$ The ranking in $R 2 m$ is also consistent with the direct estimates of Jorgensen and Gallop

\footnotetext{
${ }^{13}$ It is straightforward to show that in our model relative prices are equal to the inverse of relative TFP levels because of free factor mobility and the assumed production functions.
} 
(1992) for the period 1947-85 and Jorgensen and Stiroh (2000) for 1959-1995. $R 2 h$ is more difficult to justify with hard empirical estimates, although it should be true, on the grounds that the market can replicate a home technology but not vice versa. Anecdotal evidence in its favour abounds, as for example the statements by Reid (1934) and others cited in section 1 for manufacturing.

Assumption $R 2 h$ implies that over time the home production of goods should be transferred to the market. Equation (16) shows that the marketization force is stronger the closer substitutes home-produced goods are to market-produced goods and the bigger the difference between their TFP growth rates. Assumption $R 2 m$ and (27) imply that in the absence of home production agriculture should be losing hours to manufacturing and services and manufacturing should be losing hours to services. A sufficient condition that home production does not reverse the direction of structural change dictated by the market TFP levels is that the differentials $\gamma_{i m}-\gamma_{i h}$ have the same ranking as the market TFP growth rates, which is plausible. But because the weight of the home sector in $\gamma_{j}$ becomes progressively smaller over time through the marketization force, there is a point after which the market TFP growth rates dominate in the evolution of employment shares whatever the ranking of the home TFP levels.

The evidence that we examined in section 1 indicated that the home production of agricultural goods in the United States virtually disappeared by 1930. This suggests that home production of agricultural goods has had too small a share in overall agricultural employment to make a difference to the structural transformation out of agriculture, and at least since 1930 we can assume that the number of hours allocated to agricultural home production is practically zero. Similarly, the evidence on the home production of manufactured goods is that by 1930 it was overtaken by market production because of technological improvements in the market. This mechanism is precisely the one in our model. As with agriculture, it again suggests that after industrialization, the home sector in manufacturing became too small to make a difference in the employment reallocations dictated by market TFP levels across sectors.

But time use surveys show substantial home production of services. Why did agricultural and manufacturing home production vanish so fast and yet service home production is surviving in such big numbers? The reason is found in the way that the marketization and structural transformation forces combine to cause sector employment dynamics. Looking at agriculture, we argued that it has the highest TFP growth rate, so the sector overall is losing hours at fast rate. Moreover, the output of home production and market production are likely to be very close substitutes, and TFP in the market, because of economies of scale, is likely to be growing much faster than the productivity of food production at home. So in agriculture both the marketization force and the structural transformation force are likely to be strong and work against home production, which is likely to disappear fast.

Similarly in manufacturing, the output of the home sector is likely to be a very close substitute to the output of home production (e.g., home-made versus ready-made 
clothes), and technology in the market is likely to have risen much faster than in the home after the industrial revolution. For both these reasons, the marketization force in manufacturing is likely to be strong. But manufacturing as a whole gains labour at first from agriculture, so at least when there is a substantial agricultural sector, the structural transformation force is not strongly against home production. In the early stages of industrialization there is a tension between the two forces in the home production of manufacturing goods, the transformation out of agriculture pushing for a rise in both market and home hours and technological improvements in the market pushing for a rise in market hours and a fall in home hours. Eventually, however, and as the share of agricultural employment shrinks, manufacturing as a whole has to lose labour to services. So although we may not see the home production of manufacturing goods fall rapidly at first, it is likely to be marketized fast during the industrialization process. We argued in section 1 that early time use surveys show some home production of manufacturing goods in the very early part of the 20th century, when the home production of agricultural goods had for practical purposes vanished. But by 1930 home production of manufacturing goods had also practically disappeared.

In contrast to agriculture and manufacturing, market-produced services are not likely to be as close a substitute for home-produced services. Whereas the outputs of agriculture and manufacturing are "standardized," service output is more diverse. For example, child care, looking after needy relatives and shopping for one's own clothes are not standardized activities that have very close substitutes provided by the market. Equally importantly, because TFP growth in the production of market services is low, the marketization force for home services is likely to be weak. Opposing this weak force against home hours, there is a strong structural transformation force increasing hours of total work spent on services. The net effect on home-produced services is ambiguous, but if it is positive, it is so when agriculture or manufacturing are shedding a lot of labour, which makes the structural transformation force stronger. Eventually, when the structural transformation force weakens through the diminishing importance of agriculture and manufacturing, the marketization force takes over, leading to a shrinkage in the home sector. So in contrast to home-produced food and manufacturing goods, we are likely to observe a non-monotonic, most likely hump-shaped path for hours of work spent on home-produced services. Moreover, the marketization of home services is likely to be weak, and so the fall in home hours in the later stages of economic growth is likely to be slow, because of both a small substitution elasticity and small productivity-growth differentials between market and home. Sub-sectors within services that have either no close substitutes in the market or have practically zero TFP growth in both the market and the home, such as aspects of child care, may never marketize completely.

Figure 2 is for the United States and shows the trends in market hours of work and in the market employment shares of the three industrial sectors. ${ }^{14}$ Our model's

\footnotetext{
${ }^{14}$ The series for market hours in figure 2 is not the same as the one shown in figure 1 , which is for
} 
predictions are consistent with the broad trends that we see in the figure. The sectoral shares are consistent with the assumptions of low substitutability between their final products and the ranking of their TFP growth rates. Manufacturing employment does not fall as rapidly as agricultural employment because it produces capital goods that are needed by the expanding (market and home) service sector. More interestingly, our model's predictions are consistent with what we see in total market hours. In the early part of the twentieth century the home production of all goods is still active and the employment share of agriculture is high. Both the marketization and structural transformation forces are likely to be strong and acting in opposite directions, so a likely outcome is the absence of any significant net impact on total market hours, as shown in the figure. According to our model, in this period the home production of agriculture and manufacturing should be losing hours fast but the home production of services should be gaining them. In the middle years, which cover the middle two quarters of the century, the home production of agricultural and manufacturing practically had disappeared, but the structural transformation force out of agriculture was still strong because of the relative size of this sectors. In these circumstances the prediction of our model is that the structural transformation force should dominate the marketization of services, and so the hours allocated to the home production of services should be rising and total hours of work falling. Again, this is consistent with what we see in the figure. But eventually the structural transformation force weakens because of the shrinkage of agricultural employment, and the marketization of services takes over. The impact on overall market work should be a rise in hours, especially by women, who performed the home tasks before marketization.

\subsection{Quantitative implications}

Having established that the broad trends in the data are qualitatively consistent with the model's predictions, we investigate here more closely its quantitative implications. We focus on the period since 1930, when the home production of agriculture and manufacturing plays no role in the dynamics. This finesses the problem of having to choose parameters for the utility function and home production functions for agricultural and manufacturing goods. We choose the following parameters in our model to eliminate home production of agricultural and manufacturing goods: $\psi_{i}=1$ for $i=a, m$, which

comparable cross-country data, because of differences in coverage. The series shown in figure 2 are due to Ramey and Francis (2006) and are more general. They include unpaid family workers, selfemployed, government employment and commuting time (which is a constant 10 percent of the sum of the previous three). The source for the employment shares is the Bureau of Economic Analysis for 1929-2004 and Historical Statistics for the United States for 1899, 1909, 1919. The graph is plotted by interpolation between the data points. Agriculture includes agriculture, forestry and fisheries, industry includes mining, manufacturing, construction, utilities, transportation and communication and services all others. 
imply $z_{a}=z_{m}=1$. With market sectors only for these goods, we use $\gamma_{a}$ and $\gamma_{m}$ to denote their TFP growth rates.

We compare our model's predictions with the US time series under the assumption that the economy is on the balanced growth path that solves the maximization of (37) subject to (36). Restrictions $R 1, R 2 m$ and $R 2 h$ still hold. We have shown analytically that under the assumption $\sigma_{s}>1>\varepsilon$ and $\gamma_{a} \geq \gamma_{m}>\gamma_{s m} \geq \gamma_{s h}$, the steady state of our model generates trends in total hours and employment shares that are qualitatively consistent with the trends in the data. The objective of this section is to choose plausible parameter values to show that the analytical results are also quantitatively consistent with data for these four series.

In the steady state, given any initial values for the allocation of hours to the three market sectors and home production, the model requires six parameters to predict their entire time path. Two parameters are the elasticities of substitution, $\varepsilon$ and $\sigma_{s}$. The next three parameters are differences in TFP growth rates, $\gamma_{a}-\gamma_{m}, \gamma_{m}-\gamma_{s m}$ and $\gamma_{s m}-\gamma_{s h}$. The last parameter is the steady state investment rate, $\eta$, which gives the employment share of capital production.

The parameter $\sigma_{s}$ is the elasticity of substitution between service and home goods. Estimates in the literature are for the elasticity of substitution between aggregate market goods and service goods and they are in the range 1.5 to 2.3 (see Rupert, Rogerson and Wright 1995, McGrattan, Rogerson and Wright 1997 and Chang and Schorfheide 2003). As in our model $\sigma_{s}$ is the elasticity of substitution between home and a smaller set of goods, our $\sigma_{s}$ should be at least as large as the existing estimates. We choose the biggest of these estimates, $\sigma_{s}=2.3$.

For the elasticity of substitution $\varepsilon$ we do not have direct estimates. It is clear from (24) that in a model without home production, and because relative prices are inversely related to relative TFP levels, the own price elasticity of the three goods is $-\varepsilon$. It is also clear from (25) that in this case the slope of the regression line between changes in relative employment levels and changes in relative prices should be $1-\varepsilon$. But with home production, and because at least some market-produced services have good substitutes in home-produced services, the estimated price elasticity should be higher than $-\varepsilon$ in absolute value. Falvey and Gemmell (1996) estimate the price elasticity of the entire service sector and they find it to be -0.3 . They compare their estimate to one by Summers (1985), which is -0.06 and not significantly different from zero. Blundell et al. (1993) report a "services" price elasticity for Britain of -0.7 . However, they do not give a list of what services are included and since the budget share of their services is only 0.12 , it must be a very small list. Their estimate is comparable to the estimates obtained by Falvey and Gemmell (1996) for each of their seven sub-sectors, whose budget shares are on average of the same order of magnitude as the Blundell et al. (1993) sector. In a model with home production, the estimate $\varepsilon=0.3$ seems to be an upper bound for the elasticity of substitution, with 0 as lower bound.

With regard to the relation between employment and price changes, we regressed 
relative employment changes and relative price changes for thirteen 2-digit consumptiongoods sectors drawn from the OECD STAN database and input-output tables for 19772001, and obtained an average estimate $1-\varepsilon=0.7 .{ }^{15}$ Given the broader aggregation in this paper, the estimate $\varepsilon=0.3$ again emerges as an upper bound for the elasticity. Following these findings, we selected $\varepsilon=0.1$ as a good guess for the benchmark elasticity of substitution between our three sectors.

We use the link between relative prices and TFP levels to derive the differences in TFP growth rates. They are set to match the changes in the prices of agriculture and service goods relative to manufacturing goods. We first compute annual growth rates for each year, then take the average for the entire period. This average is 0.93 per cent for the price ratio of services to manufacturing and -1.2 for the price ratio of agriculture to manufacturing. ${ }^{16}$ These two numbers are consistent with the direct estimates of Jorgenson and Gallop (1992), who calculate an average TFP growth rate for the period 1947-85 of 2.06 per cent for agriculture and 0.82 per cent for the private non-farm sector. ${ }^{17}$ Within their non-farm sectors, TFP growth rates vary but the TFP growth rates for industrial sectors are in general higher than the ones for service sectors.

We cannot adopt the same methodology to calibrate $\gamma_{s m}-\gamma_{s h}$ as there are no estimates on the implicit price of home goods. We reason as follows. Given the observed rate of growth of aggregate labour productivity of 2 per cent and a capital share of $1 / 3$, a plausible estimate of manufacturing TFP growth is $\gamma_{m}=1.33$ per cent. If we subtract from this our computed difference between manufacturing and services, 0.93, we find $\gamma_{s m}=0.4$ per cent (which is also consistent with the direct estimates of Jorgenson and Gallop 1992 and Jorgensen and Stiroh 2000). Thus, the maximum difference between the TFP growth rates of market and home production consistent with non-negative TFP growth in the home sector is 0.4 per cent. Of course, negative TFP growth in the home sector is not inconsistent with our model or with rising labour productivity, because accumulation of consumer durables could offset it. ${ }^{18}$ Nevertheless, we use $\gamma_{s m}-\gamma_{s h}=0.004$

\footnotetext{
${ }^{15}$ These results are available in the longer version of Ngai-Pissarides (2004) that circulated as CEPR discussion paper no. 4763 and on our personal web sites.

${ }^{16}$ Source for 1929-1970: Historical Statistics of the United States: Colonial Times to 1970, Part 1 and 2. The implicit price deflator for services in series E17, and the wholesale price index for industrial commodities and farm products in series E24-25. For 1970-2000, see Economic Report of the President, Tables B-62 and B-67. The measurement of both prices and TFP, especially in the earlier period, is fraught with difficulties, so we use the same TFP differences for the whole period, rather than looking at different sub-periods, even though our balanced growth path allows $\gamma_{s m}$ and $\gamma_{a}$ to change over time.

${ }^{17}$ The numbers are obtained from adding the productivity growth rates due to input quality adjustment from Table 4 to the TFP growth rates in Table 1, 1.58 for agriculture and 0.44 for the non-farm sector.

${ }^{18}$ The capital-labour ratio in home production is $k$, the same as in the market, and so it grows at positive rate $\gamma_{m} /(1-\alpha)$. "Real" labour productivity in home production is $A_{h} k^{\alpha}$, which grows at rate $\alpha \gamma_{m} /(1-\alpha)+\gamma_{s h}$, so a negative $\gamma_{s h}$ is consistent with positive rate of growth of real labour productivity. Of course, as in the other sectors, the value of average product in the home sector (with manufacturing as numeraire) grows at rate $\gamma_{m}$ and the implicit price of home-produced goods rises at rate $\gamma_{m}-\gamma_{s h}$.
} 
Table 3: Baseline Parameters, United States, 1930-2000

\begin{tabular}{cccccc}
\hline \hline$\eta$ & $\sigma_{s}$ & $\varepsilon$ & $\gamma_{m}-\gamma_{a}$ & $\gamma_{m}-\gamma_{s m}$ & $\gamma_{s m}-\gamma_{s h}$ \\
0.104 & 2.3 & 0.1 & -0.012 & 0.0093 & 0.004 \\
\hline
\end{tabular}

as our benchmark.

Finally, the steady-state investment rate is $\eta=\eta_{m} /\left(1+l_{s h} / q\right)$, where $\eta_{m}$ is the investment (or saving) as a fraction of market production, which we get from Maddison (1992). To minimize the role of the Great Depression on the average savings rate, we use the average of $1925-30$ as an estimate for 1930 , so $\eta_{m 0}=0.189$. To compute $\eta$ we also need the initial home-to-market hour $\left(l_{s h 0} / q_{0}\right)$. We obtain this ratio from home and market hours data recently construed by Ramey and Francis (2006). To be consistent, we also use the average of $1925-30$ as an estimate for 1930 , to obtain $l_{\text {sh0 }} / q_{0}=0.812$. Therefore, $\eta=0.104$. The calibrated benchmark values are shown in Table 3 .

To construct the entire predicted path for hours since 1930 we need 1930 values for hours of work in the three market sectors and in home production. The 1930 value for the market shares and market hours are shown in figure 2. For home production we used the Ramey and Francis (2006) estimate. Because home hours in 1930 may not be accurately measured, we also experimented with initial values that are \pm 20 per cent of the Ramey-Francis data point, with virtually no impact in our predictions (the impact was too small to show on the graph below).

The results of calibrating the model are shown in figure 3. The model tracks the dynamics of employment shares very well, picking up the fast rise of service employment and the fall in agricultural employment, with smaller changes in manufacturing. With respect to total market hours, the model generates a very shallow U-shape when compared to the data. Not surprisingly, it does not track the changes in hours in the Great Depression and the war, but it picks up the downward trend up to the mid 1970s and the rise in the last quarter century. In 1930 hours of work were 28.4 per week. In 1975-84, when hours reached their lowest point, they were on average 26.6 per week. The model predicts a fall to 27.4 hours. By 1995-04, hours of work increased back to 28.3 per week, and the model predicts 27.7 per week. As we pointed out, predicting the turning point as part of the same dynamic process is unique to our model, but it is clear from the results that the productivity explanation is not the only explanation for the observed low-frequency fluctuations in hours of work. ${ }^{19}$

\footnotetext{
${ }^{19}$ Raising $\sigma_{s}$ in these calculations reduces the extent of the fall in hours but increases the subsequent rise; increasing the productivity differentials between agriculture, manufacturing and services gives a bigger fall between 1930 and the 1970s but a subsequent rise of the same order of magnitude.
} 


\section{More on the economics of leisure}

We have treated non-work time so far as in conventional growth and real business cycle models, as leisure time that yields utility directly, without the help of any goods. But a large amount of leisure in time use surveys is enjoyed with the use of some capital or intermediate goods, such as watching TV, surfing the net or talking on the telephone. We generalize our benchmark model by introducing a leisure good $c_{l}$ that is produced mostly at home using time and capital goods. ${ }^{20}$ One important outcome of this extension is that now changes in leisure time can also cause changes in labour supply, even if the economy is on a balanced growth path.

We assume that leisure is of two types, one as in the benchmark model and one that is the output of a "production" process that uses capital and labour through a production function that is identical to the one for other goods. We use subscript $l$ for leisuregoods production and let $A_{l}$ denote its TFP level. We assume that the leisure good (say TV viewing services) is a better substitute for service goods than it is for agricultural and manufacturing goods. But it is not as good a substitute for market services as home production is. This is the main feature that differentiates home production from leisure production. Home production such as cooked food has market-produced close substitutes but leisure production such as TV viewing does not have close substitutes in the market; if an individual hires somebody to do her TV viewing for her the end product will not be a close substitute to watching the TV herself. Yet both cooked food and TV viewing are produced at home with some durable good purchased from the manufacturing sector.

Formally, we assume that the services aggregate now consists of three goods, market services and home production as before, combined into $c_{s}$ as in the benchmark model, and leisure goods, which are combined with $c_{s}$ into a grand service good, $c_{S}$. We want the elasticity of substitution between $c_{s}$ and $c_{l}$ to be bigger than the one between service goods and manufacturing goods (our $\varepsilon$ ) but smaller than the elasticity of substitution between market and home produced services $\left(\right.$ our $\left.\sigma_{s}\right)$. We choose it to be 1 , which gives a particularly simple and appealing result on the dynamics of leisure time. But the model also has a solution if the elasticity is bigger or smaller than one.

The utility of goods now is,

$$
\phi(.)=\left(\sum \omega_{j} c_{j}^{(\varepsilon-1) / \varepsilon}\right)^{\varepsilon /(\varepsilon-1)} j=a, m, S ; \quad c_{S}=c_{s}^{1-\xi} c_{l}^{\xi},
$$

\footnotetext{
${ }^{20}$ In time use surveys by far the dominant good of the kind that we have in mind is watching TV. See below in this section for some data. Greenwood and Vandenbroucke (2005) also put forward the idea that the dynamics of leisure time are influenced by the complementarities between durables and time. Their approach, however, is different from ours. They claim that leisure has increased because the quality and variety of goods like TV, which are complementary to leisure time, has gone up. Our claim runs along the lines of our previous discussion, people consume more time watching TV and doing other similar things because technological progress elsewhere has increased their consumption of other goods and other goods are poor substitutes for TV watching time.
} 
with $c_{s}$ defined as before, as a CES between $c_{s m}$ and $c_{s h}$ with elasticity $\sigma_{s}$. This specification reduces to the benchmark model when $\xi \rightarrow 0$. The marketization conditions (15) still hold between the market and home production of service goods. By direct extension a similar condition holds between the service composite $c_{s}$ and leisure production $c_{l}$ :

$$
\frac{l_{l}}{l_{s}}=\frac{\xi}{1-\xi}
$$

This is an important result that is due to our unit elasticity assumption for $c_{s}$ and $c_{l}$ : the ratio of leisure-production time to service-production time is a constant. The size of the constant depends on the parameter $\xi$. It should be obvious and it is straightforward to show that all the other results of the benchmark model still hold, with the composite $c_{S}$ replacing $c_{s}$. The composite $c_{S}$ now has two "marketization" forces beneath it, the one between market production and home production which holds as before, and the one between leisure and the other two service sectors, given by (43). The aggregates (consumption, income and capital stock) are still defined as before and a balanced growth path with constant capital-output ratio exists. The new element is that on this steady state total leisure is now defined as $(1-l)+l_{l}$, and it is not constant because of the dynamics of $l_{l}$.

As in the benchmark model and for as long as TFP growth in agriculture and manufacturing exceed TFP growth in the service sectors, service employment is monotonically increasing over time. Now because of $(43), l_{l}$ is also monotonically increasing over time. Thus, total leisure time, $1-l+l_{l}$, is increasing over time, with $l$ constant on the balanced growth path and $l_{l}$ rising. We address two questions about this dynamic. First, how big is the share of leisure in time use surveys now and how big is it in the asymptotic state? This will give an idea of the dynamics involved. Second, what happens to overall labour supply when there is leisure production?

The answer to the first question depends mainly on the preference parameter $\xi$. This is because both the current and asymptotic $l_{l}$ are a constant fraction $\xi /(1-\xi)$ of service employment. In the American Time Use Surveys (ATUS) of 2003 and 2004 there is a fairly detailed breakdown of the activities in which people engage in their leisure time. We include under our leisure production TV watching, sports participation and telephone, mail and email and we find that individuals over the age of 15 spend about 21 hours a week in these activities. Total leisure time is about 39 hours and total work time (market and home) 50 hours. ${ }^{21}$ Making use of the data on home and market production from the same surveys we get an approximate value of $\xi=1 / 3$. In the asymptotic steady state our model prediction (on the assumption that the time devoted to the other activities mentioned in the preceding footnote remains the same) is that total work converges to 44 hours and total leisure time to 45 hours. So the prediction is

\footnotetext{
${ }^{21}$ The remainder is spent on essential activities like sleep, 74 hours, education, 3.5 hours and unclassified items, 1.5 hours.
} 
that once the structural transformation and marketization forces run their course, there will be a net shift of 6 hours a week from work to leisure activities. It is also predicted that the shift will take a very long time to complete because of the small differentials in the TFP growth rates.

Labour supply with leisure production is $q=l-l_{h}-l_{l}$. Since home production converges to zero and leisure converges to a constant, labour supply must also converge to a constant. Leisure is rising throughout the adjustment to the asymptotic steady state, whereas we have argued that the structural transformation and marketization forces that drive labour supply in the benchmark first lower labour supply and then increase it. So with leisure production the predicted initial fall in labour supply is faster and due to both the rise in leisure and the rise in home production, whereas in the second phase, when labour supply increases, the rise would be mitigated. Two forces are acting against each other in the second phase, the marketization of home production pushes for a rise in labour supply and the rise in leisure for a fall. With the parameter values used in our benchmark calibrations and $\xi$ set equal to $1 / 3$, the marketization force dominates and labour supply is on a very slowly increasing trend. ${ }^{22}$

\section{Conclusions}

We have shown that a unified framework can simultaneously account for structural change between agriculture, industry and services and a changing trend in aggregate hours of work without violating balanced aggregate growth. Our prediction of the coexistence of a changing trend in hours on the one hand and balanced aggregate growth on the other is new to a model of economic growth. The assumptions that drive our results are (a) market goods are poor substitutes with each other but home-produced goods have close substitutes in the market, and (b) agriculture and industry have higher rates of total factor productivity growth than do services, but within each sector market production has higher rate of TFP growth than home production. On the aggregate economy's balanced growth path the dynamics of aggregate market hours are driven by the dynamics of home production, but off the steady state there are transitional dynamics with leisure time rising and the supply of labour falling. We have also shown that an extension which refines the use of leisure time and pays attention to the fact that most leisure time is spent with some capital good, such as a TV set, has the implication that leisure time is also rising over time on the balanced growth path.

The qualitative predictions of our model are consistent with the dynamics of hours of work in the United States. Quantitative analysis shows that the model matches well the dynamics of employment shares since 1930 and reasonably well the aggregate dynamics. In particular, we explain a fall in market hours up to the 1970s and a rise

\footnotetext{
${ }^{22}$ This conclusion is consistent with the conclusion of Aguiar and Hurst (2005), who find that in recent surveys the fall in home production time has been matched mainly by a rise in leisure time.
} 
since then. The recent rise of female employment is consistent with the marketization of home production emphasized in this paper. Of course, this is not to suggest that no other factor has contributed to the explanation of the dynamics of market hours of work.

We abstracted from international trade and all distortions to competitive market allocations. Distortions can influence the allocation of time between market and home and trade affects manufacturing and services differently, so it is likely to influence structural change. European data show the same general patterns for market hours of work as in the United States, but more recently with some delay in the marketization of home production. We did not discuss in any detail reasons for these differences; taxation, regulation such as restrictions in weekly hours of work and in shop opening times and trade are likely to prove important in accounting for these differences. Future work needs to enrich the technological explanation of trends that we have emphasized in this paper with the introduction of taxes, regulation and international trade, especially is cross-country differences are to be successfully explained (see Freeman and Schettkat, 2005, Prescott, 2004, Rogerson, 2004, and Messina, 2005, for related work).

\section{References}

[1] Aguiar, M. and E. Hurst (2005). "Measuring Leisure: Evidence from Five Decades of Time Use Surveys", unpublished paper University of Chicago.

[2] Baumol, W. (1967). "Macroeconomics of Unbalanced Growth: The Anatomy of Urban Crisis", American Economic Review 57: 415-26.

[3] Blundell, R., P. Pashardes and G. Weber (1993). "What Do We Learn About Consumer Demand Patterns from Micro Data?", American Economic Review 83: 570597.

[4] Cooley, T. F., ed. (1995). Frontiers of Business Cycle Research. Princeton, NJ, Princeton University Press.

[5] Chang, Y. and F. Schorfheide (2003). "Labor-supply shifts and economic fluctuations", Journal of Monetary Economics 50: 1751-1768.

[6] Durand, J. (1975). The Labour Force in Economic Development: A Comparison of International Census Data, 1946-1966. Princeton, NJ: Princeton University Press.

[7] Echevarria, C. (1997). "Changes in Sectoral Composition Associated with Economic Growth." International Economic Review 38 (2): 431-452.

[8] Falvey, R. E. and N. Gemmell (1996). "Are Services Income Elastic? Some New Evidence." Review of Income and Wealth 42: 257-269. 
[9] Freeman, R. and R. Schettkat (2005), "Marketization of Household Production and the EU-US Gap in Work', Economic Policy, January pp. 5-50.

[10] Goldin, C. (1995). "The U-Shaped Female Labour Force Function in Economic Development and Economic History." In T. P. Schultz, ed., Investment in Women's Human Capital and Economic Development. Chicago, IL: University of Chicago Press, pp.61-90.

[11] Gollin, D., S. Parente, and R. Rogerson, (2000). "Farm Work, Home Work, and International Productivity Differences." Forthcoming in The Review of Economic Dynamics.

[12] Greenwood, J. and G. Vandenbroucke, (2005). "Hours Worked: Long-Run Trends." Research Report No. 10, Economie d'avant garde, University of Rochester.

[13] Greenwood, J., A. Seshadri and M. Yorukoglu (2005). "Engines of Liberation." Review of Economic Studies 72, 109-133.

[14] Gronau, R. (1977). "Leisure, Home Production, and Work - the Theory of the Allocation of Time Revisited." Journal of Political Economy 85: 1099-1123.

[15] Gronau, R. (1997). "The Theory of Home Production: The Past Ten Years." Journal of Labour Economics, v15: 197-205.

[16] Jorgenson, D. and F. Gallop (1992). "Productivity Growth in U.S. Agriculture: A Postwar Perspective." American Journal of Agricultural Economics 74: 745-750.

[17] Jorgenson, D. and K. Stiroh (2000). "U.S. Economic Growth at the Industry Level." American Economic Review 90 (2): 161-167.

[18] Juster, F and F. Stafford (1991). "The Allocation of Time: Empirical Findings, Behavioral Models, and Problems of Measurement." Journal of Economic Literature 29: 471-522.

[19] King, R., C. Plosser and S. Rebelo (1988). "Production, Growth and Business Cycles I. The Basic Neoclassical Model." Journal of Monetary Economics 211: 195-232.

[20] Kongsamut, P., S. Rebelo and D. Xie (2001). "Beyond Balanced Growth," Review of Economic Studies 68: 869-882.

[21] Kuznets, S. (1966). Modern Economic Growth: Rate, Structure, and Spread. New Haven, Conn.: Yale University Press. 
[22] Lebergott, S. (1993). Pursuing Happiness. Princeton University Press. Princeton, New Jersey.

[23] Leeds, J. (1917). The Household Budget: With A Special Inquiry into the Amount and Value of Household Work. Columbia University, Ph.D. dissertation.

[24] Maddison, A., (1992). "A long-run perspective on saving," Scandinavian Journal of Economics, 84: 181-196.

[25] McGrattan, E., Rogerson, R. and R. Wright (1997) "An Equilibrium Model of the Business Cycle with Household Production and Fiscal Policy." International Economic Review. 38: 267-90.

[26] Maddison, A. (1995). Monitoring the World Economy 1892-1992. Development Centre studies, OECD.

[27] Messina, J. (2005). "The Role of Product Market Regulations in the Process of Structural Change" mimeo, European Central Bank, forthcoming European Economic Review.

[28] Mitchell, B.R. (1980). European Historical Statistics, 1750-1975. London: Macmillan Press.

[29] Mokyr, J. (2000). "Why "More Work for Mother?" Knowledge and the Household Behavior, 1870-1945." Journal of Economic History, Vol. 60, No. 1, pp. 1-40.

[30] Ngai, L. R. and C. Pissarides (2004). "Structural Change in a Multi-Sector Model of Growth." American Economic Review, in press.

[31] Parente, S., Rogerson, R., Wright, R., (2000). "Homework In Development Economics: Household Production and the Wealth of Nations". Journal of Political Economy 108, 680-688.

[32] Prescott, E., (2004). "Why Do Americans Work So Much More than Europeans?" Quarterly Review of the Federal Reserve Bank of Minneapolis, July, 2-13.

[33] Ramey, V. and N. Francis. (2006). "A Century of Work and Leisure." Working Paper.

[34] Reid, M. (1934). Economics of Household Production. New York, John Wiley \& Sons, INC.

[35] Robinson, J. P. and G. Godbey (1997). Time for Life: The Surprising Ways Americans Use Their Time. University Park, PA, Pennsylvania State University Press. 
[36] Rogerson, R. (2004). "Structural Transformation and the Deterioration of European Labour Market Outcomes." Working Paper.

[37] Rupert, P., R. Rogerson and R. Wright. (1995). "Estimating Substitution Elasticities in Household Production Models." Economic Theory 6, 179-193.

[38] Summers, R.(1985), "Services in the International Economy", in R. P. Inman (ed.), Managing the Service Economy. Problems and Prospects, Cambridge University Press, Cambridge.

[39] US Bureau of the Census (1975). Historical Statistics of the United States, Colonial Times to 1970. Bicentennial Edition, Part 1 and Part 2. US Government Printing Office, Washington, DC.

[40] Vanek, J. (1973). Keeping Busy: Time Spent in Housework, United States, 19201970. The University of Michigan Ph.D. Dissertation. 


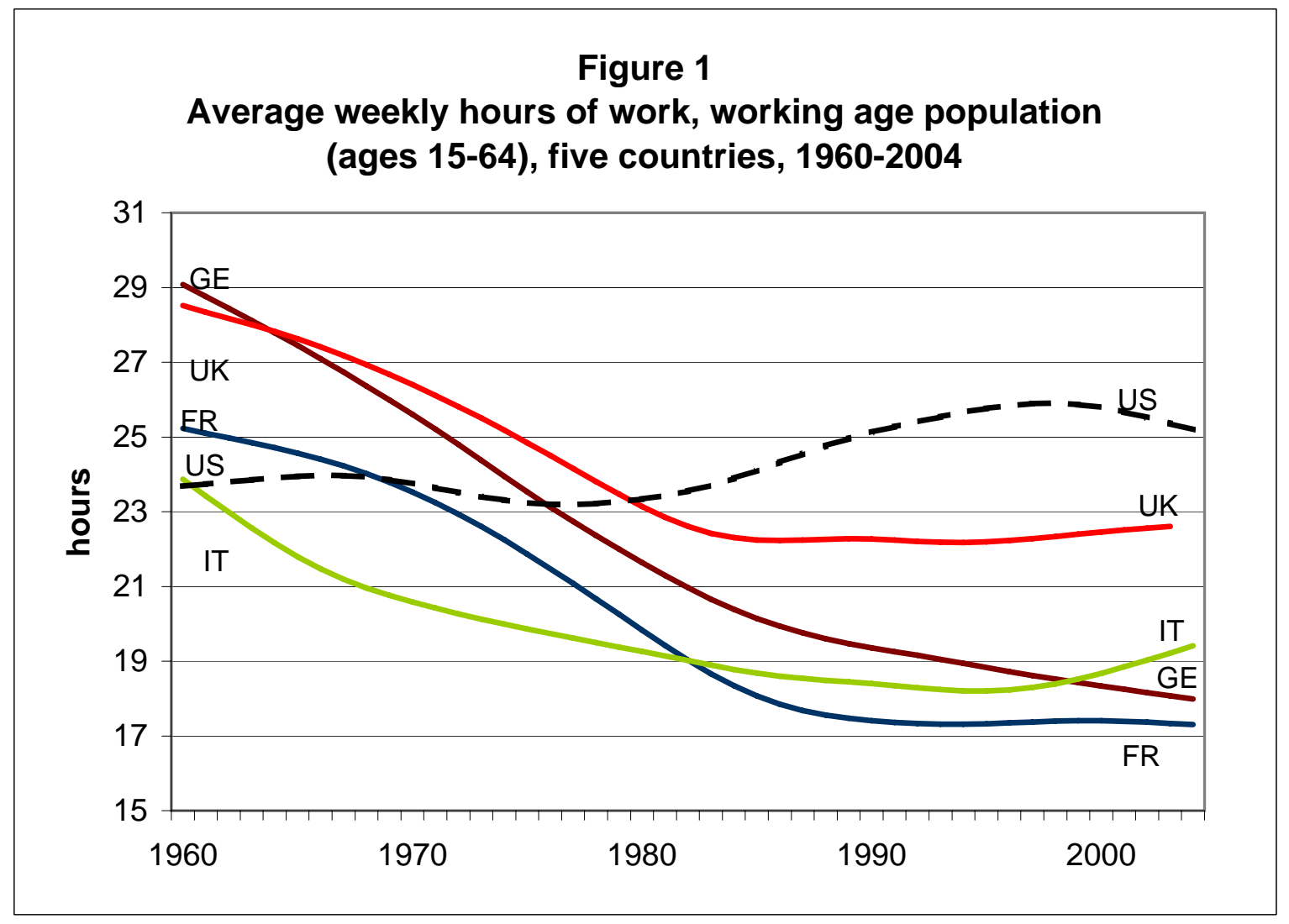

Sources: Total hours, Groningen Growth and Development Centre Working age population, OECD 


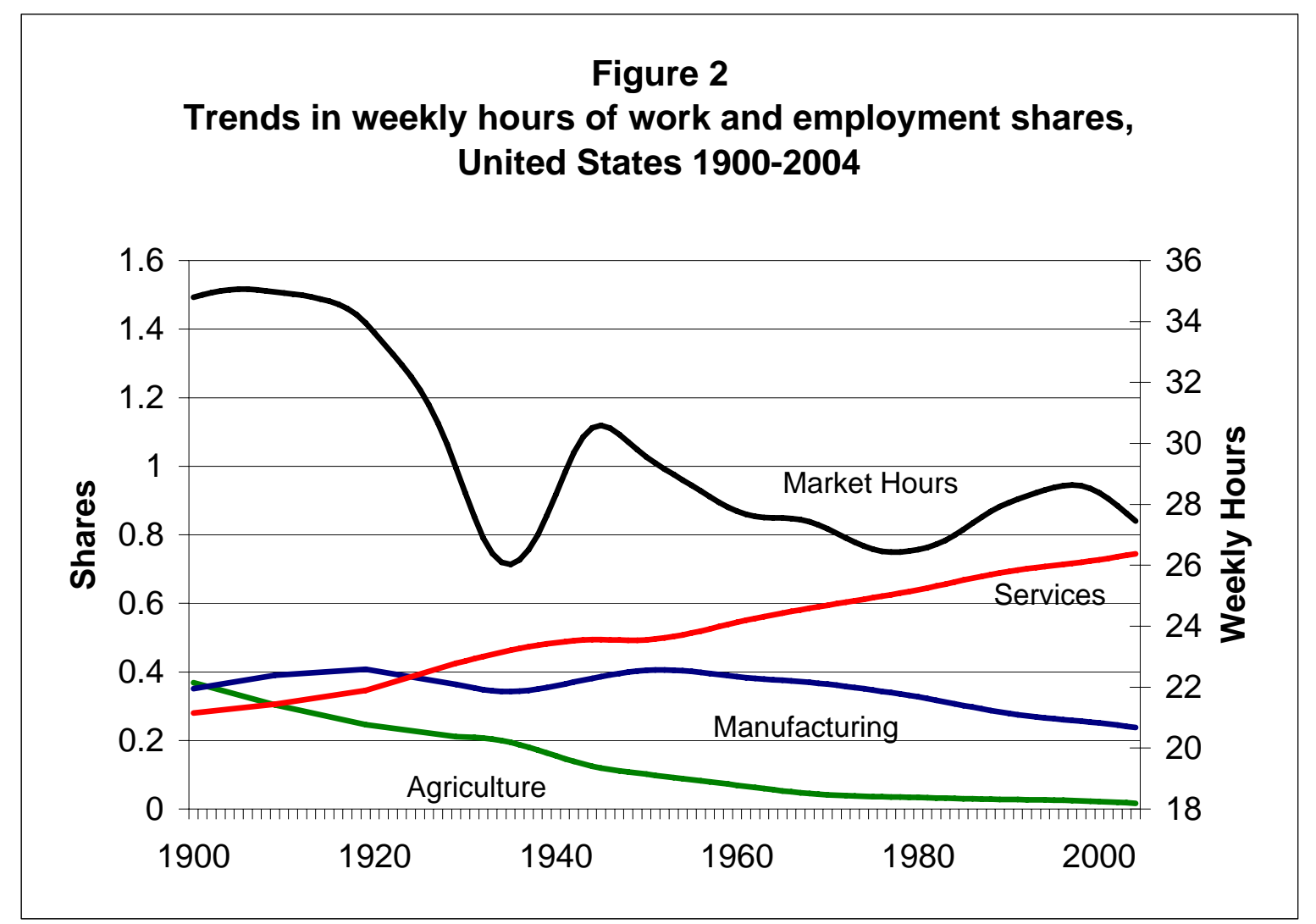

Definitions: "Agriculture" includes agriculture, forestry and fisheries; "manufacturing" includes mining, manufacturing, construction, utilities, transportation and communication and "services" all others Market Hours is total market hours divided by the working age population (ages 15-64)

Sources: Employment shares, US Historical Statistics and BEA, HP filtered.

Market Hours, Ramey and Francis (2006)

Working age population, US Census Bureau 
Figure 3

Model predictions:

Employments shares and market hours

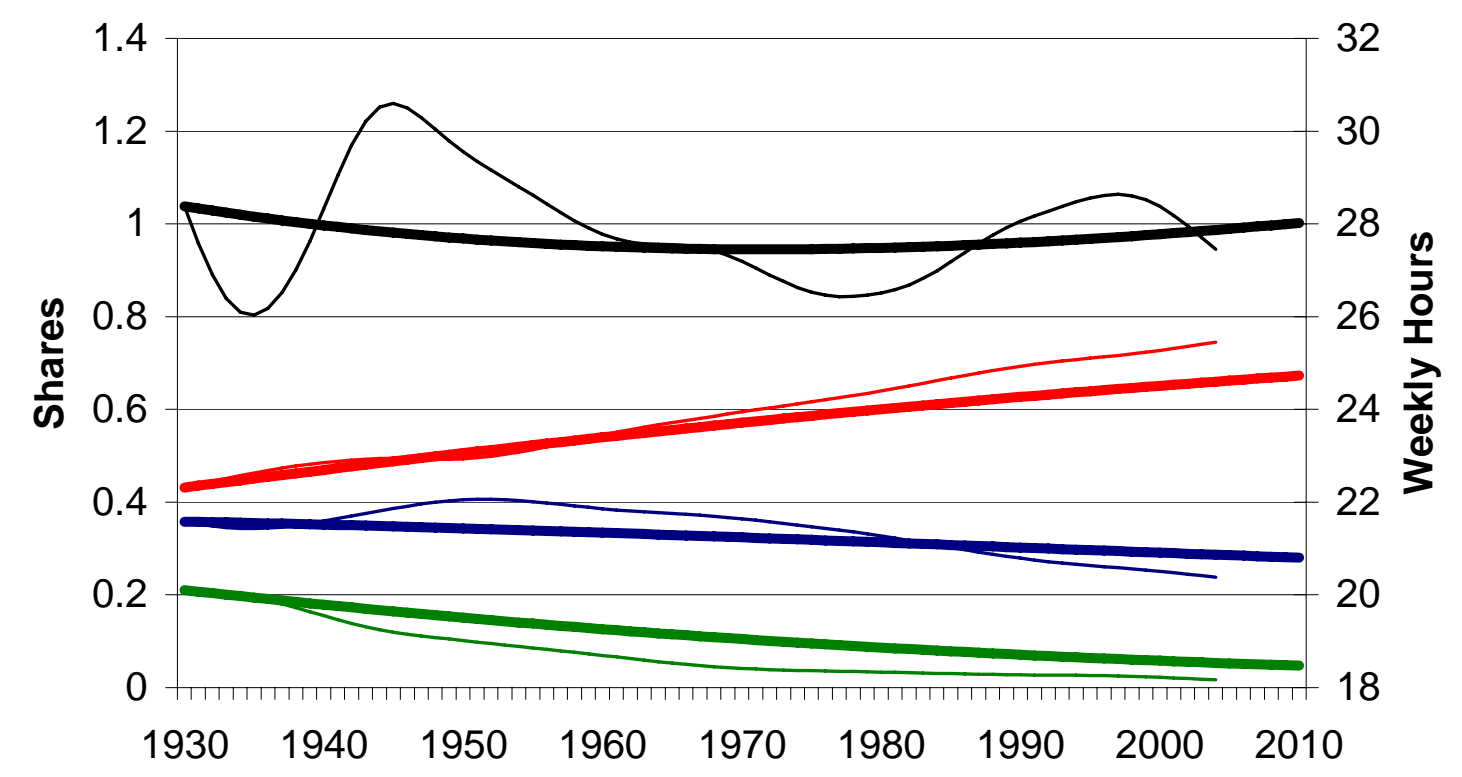

model

data 


\section{CENTRE FOR ECONOMIC PERFORMANCE Recent Discussion Papers}

745 Michael White Alex Bryson

744 Wendy Carlin Andrew Charlton Colin Mayer

743 Carlos Thomas

742 Tobias Kretschmer Katrin Muehlfeld

741 Francesco Caselli Nicola Gennaioli

740 Michael Noel Mark Schankerman

739 Nick Bloom Stephen Bond John Van Reenen

738 Sami Napari

737 Tobias Kretschmer

736 Andrew B. Bernard Stephen J. Redding Peter K. Schott

735 Francesco Caselli James Feyrer

734 Frédéric Robert-Nicoud
Unions, Job Reductions and Job Security Guarantees: the Experience of British Employees

Capital Markets, Ownership and Distance

Equilibrium Unemployment and Optimal Monetary Policy

Co-Opetition and Prelaunch in Standard Setting for Developing Technologies

Dynastic Management

Strategic Patenting and Software Innovation

Uncertainty and Investment Dynamics

The Early Career Gender Wage Gap

Competing Technologies in the Database Management Systems Market

Multi-Product Firms and Product Switching

The Marginal Product of Capital

Off-Shoring of Business Services and DeIndustrialization: Threat or Opportunity - and for Whom? 
733 Alex Bryson

Michael White

732 Francesco Caselli

Wilbur John Coleman II

731 Alex Bryson

Richard Freeman

730 Giulia Faggio

Stephen Nickell

729 Saul Lach

Mark Schankerman

728 Philippe Aghion

Robin Burgess

Stephen Redding

Fabrizio Zilibotti

727 Richard E. Baldwin

Fredéric Robert-Nicoud

726 Gustavo Crespi

Chiara Criscuolo

Jonathan Haskel

725 Giovanni Olivei

Silvana Tenreyro

724 Ghazala Yasmeen Azmat

723 Sharon Belenzon

722

Daron Acemoglu

Philippe Aghion

Claire Lelarge

John Van Reenen

Fabrizio Zillibotti
Unions, Within-Workplace Job Cuts and Job Security

Guarantees

On the Theory of Ethnic Conflict

What Voice Do British Workers Want?

Patterns of Work Across the OECD

The Impact of Royalty Sharing Incentives or Technology Licensing in Universities

The Unequal Effects of Liberalization: Evidence from Dismantling the License Raj in India

Trade and Growth with Heterogeneous Firms

Productivity, Exporting and the Learning-by-

Exporting Hypothesis: Direct Evidence from UK Firms

The Timing of Monetary Policy Shocks

The Incidence of an Earned Income Tax Credit:

Evaluating the Impact on Wages in the UK

Basic Research and Sequential Innovation

Technology, Information and the Decentralization of the Firm

\section{The Centre for Economic Performance Publications Unit Tel 02079557673 Fax $02079557595 \quad$ Email info@cep.lse.ac.uk Web site http://cep.Ise.ac.uk}

